\title{
BURDEN, TYPES OF DISEASES AND OUTCOME IN LBW (LOW BIRTH WEIGHT) BABIES ADMITTED AT A TERTIARY CARE HOSPITAL.
}

1. FCPS (Pediatrics Medicine) Assistant Professor

Sheikh Khalifa Bin Zaid Al Nahyan Teaching Hospital, Rawlakot.

2. PGR FCPS (Pediatric Medicine) Postgraduate Resident Department of Pediatric Medicine The Children's Hospital and The Institute of Child Health, Multan 3. $\mathrm{DCH}, \mathrm{MD}$

Chief Medical Officer Liaquat University Hospital, Hayderabad / Jamshoro.

Correspondence Address: Dr. Fazal Ur Rehman Department of Pediatric Medicine The Children's Hospital and The Institute of Child Health, Multan. fazal171@gmail.com

Article received on: 15/04/2019 Accepted for publication: 25/09/2019

\section{Shahid Iqbal' ${ }^{1}$, Fazal Ur Rehman ${ }^{2}$, Muhammad Haneef ${ }^{3}$}

ABSTRACT... Objectives: LBW has long been labeled as one of the major risk factor for mortality as well as morbidity in neonates. South Asia is said to have highest number of LBWs which estimated to be 1 in 4 newborns that weigh < 2500 grams. This study was planned with an aim to note the burden, types of diseases and outcome in LBW newborns admitted at a tertiary care hospital. Study Design: Descriptive analytical study. Setting: Included all neonates admitted to NICU of Sheikh khalifa Bin Zaid AI Nahyan Teaching Hospital, Rawlakot. Period: $1^{\text {st }}$ July 2018 to $31^{\text {st }}$ December 2018. Material \& Methods: The prevalence of LBW amongst all admissions was calculated along with demographic features of all LBW babies like disease, reasons for the admission, duration of hospital stay along with outcome was noted on a predesigned proforma. Results: Out of total of 1410 admission in NICU during the study period, 512 (36.3\%) were noted to be LBW. Amongst LBW babies, mean weight was $1.91 \mathrm{~kg}$ while 269 (52.5\%) were male and 243 (47.5\%) female. There were $364(67.6 \%)$ babies born at full term. There were $82(16.0 \%)$ with birth weight of less than $1.5 \mathrm{~kg}, 166(32.4 \%)$ between 1.5 to $2 \mathrm{~kg}$ while 264 (51.6\%) were above $2 \mathrm{~kg}$. Amongst all LBW babies, mortality was reported in $185(36.1 \%)$ while $112(60.5 \%)$ died on the $1^{\text {st }}$ day of admission. Respiratory distress syndrome (31.4\%), sepsis (20.3\%) and neonatal jaundice 58 (11.3\%) were the commonest diseases seen. Highest mortality (56.1\%) was seen in babies who had birth weight below $1.5 \mathrm{~kg}$ ( $\mathrm{p}$ value = 0.001). Conclusion: LBW is a major cause of hospitalization and mortality. RDS and sepsis were the most frequent diseases noted in LBW babies. Immediate care following birth is vital for babies already at risk of LBW.

Key words: $\quad$ Low Birth Weight, Mortality, NICU, Respiratory Distress, Sepsis.

Article Citation: Iqbal S, Fazal ur Rehman, Haneef M. Burden, types of diseases and outcome in LBW (Low Birth Weight) babies admitted at a Tertiary Care Hospital. Professional Med J 2020; 27(3):547-551.

DOI: 10.29309/TPMJ/2020.27.3.3551

\section{INTRODUCTION}

Neonatal mortality is estimated to be responsible for $45 \%$ deaths under the age of 5 years. Out of these, low birth weight (LBW) are documented to contribute somewhere between $60-80 \%$ of deaths. ${ }^{1,2}$ The worldwide prevalence of LBW is approximation $16 \%$ whereas more than $95 \%$ of these are from developing countries. ${ }^{3}$

LBW has long been labeled as one of the major risk factor for mortality as well as morbidity in neonates. ${ }^{4}$ South Asia is said to have highest number of LBWs which estimated to be 1 in 4 newborns that weigh $<2500$ grams. Pakistan is ranked third globally when it comes to newborn mortality rates, while in 2013, UNICEF declared Pakistan to have $32 \%$ rates of LBW newborns, considered to be $2^{\text {nd }}$ highest in the world. ${ }^{5,6,7}$

World Health Organization describes low birth newborns as those born having weight $<2500$ grams. ${ }^{8}$ LBW newborns are considered to be more prone to various kinds of infection that may go on to cause deaths in those newborns. Those surviving the early phase usually grow up to be malnourished while many of these children have limited physical as well as intellectual abilities in the years to follow. These LBW newborns are also considered to be more susceptible to diabetes and cardiovascular diseases. ${ }^{9,10}$

Considered to be a complex phenomenon, preterms and small for gestation age newborns seem to form a major part of LBW newborns. ${ }^{11}$ 
Better healthcare facilities especially in developing countries at preconception phase along with improved antenatal, intrapartum and postnatal stages are thought to reduce the neonatal mortality by $71 \%$ by year $2025 .^{12}$

Documentation and analysis of burden, patterns and outcome related to LBW forms the basis for devising a viable strategy for future in a country like Pakistan where not much research is seen over the years in LBW neonates, this study was planned with an aim to note the burden, types of diseases and outcome in LBW newborns admitted at a tertiary care hospital.

\section{MATERIAL \& METHODS}

This was a descriptive analytical study included all neonates admitted to NICU of Sheikh Khalifa Bin Zaid Al Nahyan Teaching Hospital, Rawlakot, from $1^{\text {st }}$ July 2018 to $31^{\text {st }}$ December 2018. The study was approved by institute's ethical and research committee. Consent was sought from parents or guardians of all neonates.

The prevalence of LBW $(<2500$ grams $)$ amongst all admissions was calculated whereas demographic features of all LBW babies like disease, reasons for the admission, duration of hospital stay along with outcome was noted on a predesigned proforma.

Neonates were placed in three weight categories, less than $1.5 \mathrm{~kg}, 1.5$ to $2 \mathrm{~kg}, 2 \mathrm{~kg}$ to $2.5 \mathrm{~kg}$ and compared for various study variables like gender, gestational age, duration of hospital stay and outcome were recorded. Chi square test was applied to note the association of studied variables whereas a $p$ value of less than 0.05 was taken as of statistical significance.

\section{RESULTS}

Out of total of 1410 admission in NICU during the study period, 512 (36.3\%) were noted to be LBW. The mean weight amongst LBW babies was noted to be $1.91 \mathrm{~kg}$ with a standard deviation of $0.32 \mathrm{~kg}$.

Among these 512 LBW babies, 269 (52.5\%) were male and 243 (47.5\%) female. There were
166 (32.4\%) babies who were born as pre-terms (before 37 weeks) while 364 (67.6\%) who were born at full term (37 to 42 weeks).

There were $82(16.0 \%)$ babies who had birth weight of less than $1.5 \mathrm{~kg}, 166$ (32.4\%) between 1.5 to $2 \mathrm{~kg}$ while 264 (51.6\%) were above $2 \mathrm{~kg}$.

The mean duration of stay among all the babies was 5.6 days with a standard deviation of 2.4 days. The duration of stay amongst 296 (57.8\%) babies was noted to be less than or equal to 3 days whereas 66 (12.9\%) had a stay over 10 days or more.

Amongst all LBW babies, mortality was reported in 185 (36.1\%) whereas 327 (63.9\%) survived and got discharged. It was noted amongst babies who died that $112(60.5 \%)$ died on the $1^{\text {st }}$ day of admission.

Most babies, 161 (31.4\%) had respiratory distress syndrome at the time of admission, sepsis 104 (20.3\%), neonatal jaundice 58 (11.3\%), congenital heart disease 42 (8.2\%), 18 (3.5\%) seizures, meconium aspiration syndrome $5(2.7 \%)$, and other diseases 38 (7.4\%).

When babies were compared in terms of their birth weight, highest mortality was seen in babies who had birth weight below $1.5 \mathrm{~kg}, 56.1 \%$ of these newborns died.

Amongst the birth weight groups, statistical significance was seen ( $p$ value $=0.001$ ). It was noted that lower the birth weight, more the mortality reported. It was also noted that 48 $(58.5 \%)$ babies in the birth weight group of less than $1.5 \mathrm{~kg}$ were pre-terms while 52 (31.3\%) with a birth of 1.5 to $2 \mathrm{~kg}$ and 66 (25.0\%) in the birth weight group as more than $2 \mathrm{~kg}$.

The relation between birth weight and gestational age status was found to be statistically significant ( $p$ value $=0.001)$. There was no difference in terms of gender between the studied populations ( $p$ value $>0.05$ ) 


\begin{tabular}{|c|c|c|c|c|}
\hline \multirow{2}{*}{ Study Variables } & \multicolumn{3}{|c|}{ Birth Weight (kg) } & \multirow{2}{*}{ P-Value } \\
\hline & $<1.5(n=82)$ & $1.5-2(n=166)$ & $>2(n=136)$ & \\
\hline \multicolumn{5}{|l|}{ Gender } \\
\hline Male & $34(41.5 \%)$ & $73(44.0 \%)$ & $136(51.5 \%)$ & \multirow{2}{*}{0.155} \\
\hline Female & 48 (58.5\%) & 93 (56.0\%) & $128(48.5 \%)$ & \\
\hline \multicolumn{5}{|l|}{ Term/Preterm } \\
\hline Preterm & 39 (45.9\%) & $114(68.7 \%)$ & 198 (75.0\%) & \multirow{2}{*}{0.001} \\
\hline Term & $43(44.1 \%)$ & $52(31.3 \%)$ & $66(25.0 \%)$ & \\
\hline \multicolumn{5}{|l|}{ Outcome } \\
\hline Died & $46(56.1 \%)$ & $65(39.2 \%)$ & $74(28.0 \%)$ & \multirow{2}{*}{0.001} \\
\hline Survived & 36 (43.9\%) & $101(60.8 \%)$ & 190 (72.0\%) & \\
\hline \multicolumn{5}{|c|}{ Table-I. Relation of Birth Weight With Regards to Gender, Term/Preterm and Outcome. } \\
\hline \multicolumn{3}{|c|}{ Disease } & \multicolumn{2}{|c|}{ Number (\%) } \\
\hline \multicolumn{3}{|c|}{ Respiratory Distress Syndrome } & \multicolumn{2}{|c|}{$161(31.4 \%)$} \\
\hline \multicolumn{3}{|l|}{ Sepsis } & \multicolumn{2}{|c|}{$104(20.3 \%)$} \\
\hline \multicolumn{3}{|l|}{ Neonatal Jaundice } & \multicolumn{2}{|c|}{$58(11.3 \%)$} \\
\hline \multicolumn{3}{|c|}{ Congenital Heart Disease } & \multicolumn{2}{|c|}{$42(8.2 \%)$} \\
\hline \multicolumn{3}{|l|}{ Seizure } & \multicolumn{2}{|c|}{$18(3.5 \%)$} \\
\hline \multicolumn{3}{|c|}{ Meconium Aspiration Syndrome } & \multicolumn{2}{|c|}{$16(3.1 \%)$} \\
\hline
\end{tabular}

Table-II. Frequency of Common Diseases among LBW babies.

\section{DISCUSSION}

LBW contributes significantly in terms of morbidity and mortality not only in infancy but in the later years of life as well. The burden of LBW is increased in developing countries. We noted the prevalence of LBW as $36.3 \%$ during the study period. Our results were quite close to some other studies like a study conducted at NICU of a Military Hospital in Rawalpindi during 2013-2014 ${ }^{13}$ recorded $38 \%$ babies having LBW while in another study from Peshawar Teaching Hospital ${ }^{14}$, this was noted to be $41 \%$. A study from Sir Ganga Ram Hospital from Lahore ${ }^{15}$ noted a much increased prevalence of LBW as $49.3 \%$ during the study Period. A study from Nigerian population ${ }^{16}$ noted $40 \%$ newborns with LBW while from India ${ }^{17}$, figures of around $20 \%$ are seen.

Predominance of male among LBW newborn was evident in our study where we noted $52.5 \%$ to be male. Similar findings were seen by other local as well as international studies ${ }^{16,18}$ where they got more males as compared to females but this difference did not seem to be of statistical significance.
In the present study, it was noted that $60.5 \%$ deaths were documented on the $1^{\text {st }}$ admission day. A study from Rawalpindi ${ }^{13}$ depicted similar findings where they noted that $55 \%$ of deaths happened on the $1^{\text {st }}$ day of life. A first day mortality rate of $44 \%$ was reported from another study conducted in Rawalpindi. ${ }^{19}$ Being a tertiary care hospital, most complicated and serious cases are reported in our hospital which emphasizes the need for better healthcare facilities.

An overall survival rate of $63.9 \%$ was noted in our study that is much better than another local study conducted in $2015^{13}$ where they noted the survival rate to be $56 \%$. Our results were closer to findings noted in Peshawar ${ }^{14}$ but better than those found from Lahore (53\%). ${ }^{15}$ Studies from developed countries like the one conducted in Johannesburg ${ }^{13}$ showed a survival rate of $72 \%$ amongst LBW babies, again proving better healthcare facilities in developed countries. It is commonly seen that many LBW babies die even before being reported to tertiary care centers. ${ }^{13}$ Increased gestational age has been seen to improve the survival rate of the newborns. It was noted in the present study that 48 (58.5\%) babies 
in the birth weight group of less than $1.5 \mathrm{~kg}$ were pre-terms where highest mortality was reported while $52(31.3 \%)$ preterm with a birth of 1.5 to $2 \mathrm{~kg}$ and $66(25.0 \%)$ in the birth weight group as more than $2 \mathrm{~kg}$. A local study from Rawalpindi found minor difference in terms of mortality between babies of different gestational ages. ${ }^{13}$

We found RDS (31.4\%), sepsis (20.3\%), and neonatal jaundice (11.3\%) to be commonest problems with LBW babies. It has been found earlier in another local study ${ }^{13}$ that RDS (28\%) was the most frequently associated disease with LBW newborns while a study from Peshawar ${ }^{14}$ noted LBW newborns to be $25 \%$ with RDS. Our data showed very similar finding to study conducted at Lahore ${ }^{15}$ in terms of sepsis where they noted $19 \%$ LBW neonates while another local study from Lahore noted these numbers to be as high as $41 \%$ while a study from South Africa $^{18}$ got $29 \%$ newborns with LBW to have sepsis. RDS and sepsis were noted to be most frequent from another local study conducted in Karachi ${ }^{20}$ as well. These differences between disease frequencies could be attributed to difference in diagnostic criteria and definition among different researchers.

There were few limitations of this study as we did not evaluate the risk factors among LBW newborns which could have given us direction towards minimizing the risk for development of this phenomenon. This was a study conducted at a one center so we cannot generalize these results for other centers as studies with bigger sample sizes involving multiple centers will further verify the results of these findings. We could not keep proper tracking of the referred cases in terms of time taken to reach our healthcare facility.

\section{CONCLUSION}

LBW is a major cause of hospitalization and mortality. RDS and sepsis were the most frequent diseases noted in LBW babies. Immediate care following birth is vital for babies already at risk of LBW.

\section{Copyright@ 25 Sep, 2019.}

\section{REFERENCES}

1. Mitao M, Philemon R, Obure J, Mmbaga BT, Msuya $\mathrm{S}$, Mahande MJ. Risk factors and adverse perinatal outcome associated with low birth weight in Northern Tanzania: a registry-based retrospective cohort study. Asian pacific journal of Reproduction. 2016 Mar $1 ; 5(1): 75-9$.

2. WHO. Maternal, newborn, Child and adolescent health. [Internet]. Geneva: World health Organization; 2014.

3. WHO. World health statistics. Geneva: World health Organization 2014. Available from http://www.who.int/ about/licensing/copyright_form/en/index.html

4. Talie A, Taddele M, Alemayehu M. Magnitude of low birth weight and associated factors among newborns delivered in Dangla primary hospital, Amhara regional state, Northwest Ethiopia, 2017. Journal of pregnancy. $2019 ; 2019$.

5. UNICEF. Nutrition- low birth weight babies. [Internet]. 2014. [updated Feb 2014, cited 2015 April 22]. Available from http://data.unicef.org/nutrition/ lowbirthweight\#sthash. EP2saxBo.dpuf

6. Bhutta ZA, Hafeez A, Rizvi A, Ali N, Khan A, Ahmad F et al. Reproductive, maternal, newborn, and child health in Pakistan: Challenges and opportunities. Lancet. 2013; 381(9884):2207-18.

7. CDC. Center for disease and Control. [Internet]. 2009. [Updated Oct 2009, cited 2015 April].

8. Available from. http://www.cdc.gov/pednss/what_is/ pednss_health_indicators.htm

9. WHO. WHA Global Nutrition Targets- Brief Nutrition policy Geneva: World Health Oanization. 2014.

10. Park K. Preventive \& Social Medicine. $21^{\text {st }}$ ed. India: Bnardsidas Bhanot; 2012.

11. Kayode GA, Amoakoh-Coleman M, Agyepong IA, Ansah E, Grobbee DE, Klipstein-Grobusch K. Contextual risk factors for low birth weight: a multilevel analysis. PloS one. 2014;9(10).

12. Bhutta ZA, Das JK, Bahl R, Lawn JE, Salam RA, Paul VK, et al. Can available interventions end preventable deaths in mothers, newborn babies, and stillbirths, and at what cost? The Lancet. 2014; 384(9940):347-70.

13. Masood S, Rahman MU, Saleem S, Hussain A, Rehman $A R$, Nudrat A, et al. Burden, outcome and diseases of low birth weight babies - A descriptive study in Military Hospital, Rawalpindi. Pak Pediatr J 2015; 39(4):217-21. 
14. Rahman S, Mahfooz T, Mahmood K. An analytic study of prevalence, birth weight and gestational age specific mortality of AGA and SGA low birth weight babies in Khyber Teaching Hospital, Peshawar. Pak Pediatr J. 2009; 33(3):174-8.

15. Seyal T, Husnain F, Anwar A. Audit of Neonatal Morbidity and Mortality at Neonatal Unit of Sir Gangaram Hospital Lahore. Ann King Edward Med Coll. 2011;17(1).

16. Agrawal VK, Agrawal P, Chaudhary V, Agarwal K, Agarwal A. Prevalence and determinants of "low birth weight" among institutional deliveries. Ann Nigerian Med 2011; 5:48-52.
17. Kader M, Perera NK. Socio-economic and nutritional determinants of low birth weight in India. N Am J Med Sci. Jul 2014; 6(7):302-08.

18. Ballot DE, Chirwa TF, Cooper PA. Determinants of survival in very low birth weight neonates in a public sector hospital in Johannesburg. BMC pediatrics. 2010; 10:30.

19. Zulfqar R, Naeemullah S. Neonatal mortality: Review from a Tertiary Hospital in Rawalpindi. JRMC; 2009; 13(1):2-6

20. Mustufa MA1, Korejo R, Shahid A, Nasim S. Infection remains a leading cause of neonatal mortality among infants delivered at a Tertiary Hospital in Karachi, Pakistan. J Infect Dev Ctries. 2014 Sep; 8(11):1470-5.

\begin{tabular}{|c|c|c|c|}
\hline \multicolumn{3}{|c}{ AUTHORSHIP } & AND CONTRIBUTION DECLARATION \\
\hline Sr. \# & Author(s) Full Name & \multicolumn{1}{|c|}{ Contribution to the paper } & Author(s) Signature \\
\hline 1 & Shahid lqbal & $\begin{array}{l}\text { Methodology, Data collection, } \\
\text { Review of literature. } \\
\text { Methodology, Literature review, }\end{array}$ \\
\hline 2 & Fazal Ur Rehman & $\begin{array}{l}\text { Discussion, Data analysis, } \\
\text { Drafting. } \\
\text { Methodology, Literature review, } \\
\text { Drafting, Proof Reading. }\end{array}$ \\
\hline
\end{tabular}

